\title{
Opinião de DiPLOMAdOS SOBRE O Curso de Psicologia da UFF
}

\author{
Francisco de Assis Palharini \\ Desirée Barros Palharini ${ }^{\star \star}$
}

\begin{abstract}
Resumo
Este estudo relata resultados de pesquisa realizada entre diplomados do curso de Psicologia da UFF com objetivo de investigar a condição de trabalho destes ex-alunos, a contribuição do curso para a inserção profissional, como avaliam o curso e qual é a imagem que fazem da instituição. Os resultados indicam que a escolha do curso deveu-se mais a fato de ser uma instituição gratuita e que sua opção pela carreira deveu-se mais a uma decisão pessoal. Consideram que o perfil profissional produzido é bom e tendem a avaliar o curso como "ótimo", com forte ênfase nos aspectos sociais e politicos da profissão. Avaliam os docentes de forma positiva, mas indicam uma relativa insatisfação em relação à metodologia de ensino utilizada. As expectativas iniciais destes diplomados estavam sensivelmente orientadas para o mercado de trabalho e consideram que o curso ajudou em sua carreira profissional. A quase totalidade da amostra está empregada e atua na área.
\end{abstract}

Palavras-chave: diplomados; egressos; sucesso acadêmico.

\section{GraduATED OPINION ABOUT UFF's Psychology Course}

\begin{abstract}
It shows results of research lead with graduated in the course of Psychology of UFF objecting to investigate their working condition in that period, the contribution of the course for professional insertion, how they evaluate the course and the image they make of the institution. The results gotten with a sample of 38 respondents who answered the proposed instrument shows that the choice of the course was more because it is a free institution and their option for this career was a personal decision. They consider that the profile of the professional graduated in this institution is good and tend to evaluate the course as "great". They point to a

^ Doutor em Educação pela Universidade Federal Fluminense, professor Associado I do Departamento de Psicologia da Universidade Federal Fluminense, diretor do Instituto de Ciências Humanas e Filosofia (terceiro mandato). Endereço: Universidade Federal Fluminense, Departamento de Psicologia. Campus do Gragoatá s/nº $3^{\circ}$ andar São Domingos. CEP: 24110350. Niteroi, RJ - Brasil.

E-mail: palharin@nitnet.com.br

$\star \star$ Professora do Departamento de Administração da UFF.

E-mail desiree@nitnet.com.br
\end{abstract}


strong emphasis in the social and political aspects of the profession. They evaluate the professors in a positive way, but they indicate some non satisfaction with the methodology of education used. The initial expectations of these graduated were significantly guided for the work market and they consider that the course helped in their professional career. Almost the totality of the sample is employed and works in the Psychology area in a satisfactory way.

Keywords: graduated; egresses; academic success.

O objetivo principal deste estudo foi investigar como os alunos do curso de psicologia da UFF estão se inserindo no mercado de trabalho, como avaliam o curso realizado e qual é a imagem que fazem do curso e da instituição. Sua função é contribuir para a melhoria das condições de ensino no curso. Os dados brutos utilizados para fins da análise realizada foram extraídos do Relatório Geral de uma pesquisa conduzida em 1999 pela Coordenadoria de Avaliação da PROAC/CPAIUFF, cujo título foi Valeu a pena $?^{1}$ (PROAC/CPAIUFF, 1999). Os dados aqui apresentados ganham relevância na medida em que se configuram como a primeira abordagem de avaliação realizada entre diplomados nesta instituição, além, obviamente, da natureza das informações que oferece sobre o ensino ministrado.

Antes de analisarmos os dados obtidos com este estudo, cabem algumas reflexões sobre a natureza de tal estudo, bem como dos padrões de investigação que tem orientado a grande maioria dos realizados com o mesmo objetivo.

Os procedimentos de Avaliação Institucional comportam, no âmbito da graduação, a análise de várias dimensões da ação educativa, dentre as quais se destaca a análise do impacto de como a formação oferecida implica a sociedade que recebe os diplomados pela instituição. Este impacto é considerado, via de regra, em função do grau de empregabilidade e sucesso profissional correspondente. O pressuposto é que, se a formação oferecida é boa, então os diplomados pelo curso teriam mais facilidades em obter emprego, bem como em ter sucesso e possibilidades mais amplas de promoção e ascensão profissional. Neste sentido tem-se tornado comuns os estudos relacionados a trajetória profissional dos exalunos (diplomados), os quais são considerados imprescindíveis ao se proceder a avaliação de um determinado curso.

Esta perspectiva que orienta os estudos sobre egressos, relacionada ao impacto da formação no meio profissional, tem suas bases no pensamento utilitarista que impregna os modelos de avaliação centrados nos resultados observáveis obtidos. Para este modelo, o sucesso da boa formação pode ser medido pela trajetória profissional dos ex-estudantes. Se conseguirem emprego, se o salário é bom, se estão tendo ascensão profissional, então, a formação oferecida é boa. No Brasil, esses estudos ganharam densidade e prestígio a partir daqueles relacionados à trajetória profissional de ex-estudantes da USP (SCHWARTZMAN, 1991; SCHWARTZMAN; CASTRO, 1991), desenvolvidos no âmbito 
do NUPES - Núcleo de Pesquisas sobre Ensino Superior da USP, considerados por Palharini, F. (1998) como sendo um importante formulador teórico das políticas oficiais de avaliação do ensino superior a partir dos anos 1990.

Reconhecemos a importância desse argumento ou desse padrão de referência para a avaliação da qualidade de um curso, assim como sua disseminação no senso comum, ou mesmo no meio acadêmico e entre estudiosos da avaliação. No entanto, reduzir a avaliação de um curso aos seus resultados observáveis e/ou mensuráveis do ponto de vista utilitarista significa reduzir essa formação ao atendimento das necessidades do mercado de trabalho. Queremos dizer com isso que o processo formativo na graduação transcende a estes limites. Ele implica a formação de um determinado tipo de profissional e cidadão, em um determinado contexto social. Assim, os valores e a identidade ético-política dos diplomados também compõem a qualidade produzida por um curso. Deste modo, ressalta-se a necessidade de que o processo avaliativo enfoque fundamentalmente o processo de produção do profissional, isto é, o modo como este profissional está sendo produzido.

Mesmo considerando que o Projeto Pedagógico do curso consiste em produzir exclusivamente um profissional competente tecnicamente, há de se reconhecer que tal proposta traz no seu bojo um determinado conjunto de valores, os quais se configuram como referência do profissional por ele formado. Em outras palavras, conforme sublinha Palharini, F. (1999) o conceito de qualidade não se expressa por si só, mas sempre em referência a algo, pois se constitui em um atributo. Assim, torna-se necessário explicitar sob qual referencial está-se considerando que algo tem qualidade e sob quais parâmetros está-se avaliando. Consideramos, portanto, que não basta a adoção de critérios de qualidade estabelecidos em outros contextos e condições (PALHARINI, F., 1999).

A característica principal dos estudos relacionados ao impacto da formação oferecida centra-se sobre os resultados ou produtos das IES. Esses estudos foram denominados impact of college on students e não se limitavam aos aspectos cognoscitivos, isto é, ao quanto aprendem os estudantes em determinados aspectos. Os antecedentes destes trabalhos remontam ao final da década de 1920, depois de um período de expansão acelerada na educação norte-americana, quando foi sentida a necessidade de se conhecer melhor qual era realmente o impacto da educação universitária sobre os estudantes (HALPERN, 1987). Eles davam muita importância aos aspectos afetivos, como, por exemplo, ao investigar como mudam as atitudes e valores dos egressos de IES em comparação com os que não chegaram a esse nível educativo (RESNICK; GOULDEN, 1987). As falhas metodológicas existentes, no entanto, impediram que essas técnicas se desenvolvessem mais efetivamente, o que só veio a ocorrer no final da década de 1960, quando adotaram uma orientação mais básica e menos aplicada.

Nesta perspectiva não se trata de documentar a excelência por meio de variáveis escassamente relacionadas à aprendizagem ou à reputação institucional no campo da investigação. Do mesmo modo, não se trata de inferir que há qualidade fixando-se em escalas de opiniões, no número de volumes na biblio- 
teca, nas taxas de retenção, na análise dos projetos pedagógicos ou nas características do corpo docente e da infra-estrutura do curso. Eles procuram avaliar a qualidade educativa mais diretamente, analisando quanto aprendem de fato os alunos e como o conseguem.

Pode-se aceitar, sem muita dificuldade, a afirmação de que uma instituição de educação superior somente oferecerá uma educação de qualidade se corresponder às necessidades da sociedade em que se encontra imersa, embora não seja tarefa fácil especificar quais são essas necessidades. Considerando, no entanto, que a educação superior tem por objetivo, além do exercício profissional, a inserção do jovem no meio social de forma autônoma, ética e com capacidade de promover transformações que façam avançar a sociedade tanto em termos econômicos quanto sociais, cabe também indagar, nos estudos entre diplomados, a quem este profissional deveria atender e a quem está atendendo, com que valores os diplomados estão atuando profissionalmente e promovendo transformações no meio social em que se inserem.

A idéia de que o impacto da educação superior oferecida deve estar intimamente relacionada às necessidades do meio social não pode, portanto, ser reduzida às necessidades da formação profissional, ao grau de empregabilidade, à natureza do emprego e/ou ao salário que os diplomados estão recebendo. $\mathrm{O}$ conceito de necessidade é um conceito relacional, que nos remete à distância que separa duas realidades muito distintas; a atual, que é o momento presente, e a futura - desejada, considerada como aquela que deveria ser. E esta relação não pode ser pensada por meio de redutores (PALHARINI, F., 1999).

Configura-se, desse modo, que o conceito de qualidade aplicado à educação, assim como no mundo dos negócios, não é um conceito claro, objetivo e universal. As definições de qualidade são produzidas, no caso da educação, em função dos projetos de sociedade que a escola pode contribuir para produzir. São projetos que prevêem formas de levar os seres humanos a comportarem-se de determinados modos, a pensarem em certa direção, a ocuparem determinados tipos de funções no sistema produtivo, a representarem determinados tipos de papéis sociais, a ordenarem ou cumprirem ordens, a serem disciplinados, dinâmicos, conformados, lideranças ou cérebros da ordem social. A qualidade, portanto, do processo educativo implica necessariamente que as concepções de homem e de sociedade, presentes nos projetos políticos que aspiram à hegemonia em determinado momento histórico, assumam a feição de um ensino determinado/modelar.

Compreendemos, portanto, que o conceito de qualidade em educação reveste-se de um caráter ideológico, tendo, inclusive, um caráter de classe; não é neutro, nem atende a interesses comuns. Resulta de definições e interesses originários de setores sociais que aspiram fazer da escola um espaço de exercício da hegemonia; são setores que enxergam no sistema escolar um locus de exercício do poder e, principalmente, de preparação/formação de quadros para o exercício ou continuidade dessa hegemonia. A definição do que ensinar e de como ensinar - pilares fundamentais de caracterização da qualidade pretendida - está submetida a estes interesses. As características do ensino oferecido, o maior ou menor 
grau de autonomia em sua aplicação, as determinações legais que pesam sobre ele, o tipo de currículo que irá representá-lo, entre outras coisas, pesam e interferem na definição de sua qualidade.

Se considerarmos que um dos objetivos da universidade e da formação superior por ela oferecida é provocar mudanças no contexto no qual se insere, é pertinente indagar qual o significado desta formação? O que ela abrange ou deveria abranger? Qual a natureza do impacto que ela promove no contexto em que se insere? Em que tipos de impactos sociais podemos nos referenciar, além daqueles relacionados diretamente à vida profissional?

Segundo Morin (2000a), as sociedades atuais estão a exigir, cada vez mais, a participação de cidadãos não somente qualificados para o trabalho, mas principalmente aptos a refletir e produzir novos conhecimentos acerca de sua prática profissional. Para Morin é preciso estabelecer uma distinção clara entre ensino superior e educação superior. Este autor toma como referência a concepção de que a graduação consiste fundamentalmente em um nível mais elevado de ensino, estamos, de algum modo, enfatizando as competências e habilidades transferidas para o estudante. Nesta perspectiva, o caráter tecnicista e orientado para as necessidades do mundo do trabalho se ressalta. Por outro lado, quando tomamos a graduação como educação superior, estamos nos referindo à utilização de meios que permitem assegurar a formação e o desenvolvimento do ser humano. Através desta concepção busca-se encorajar o autodidatismo e estimular e facilitar a autonomia do espírito. Não se trata de privilegiar o mero saber, mas, antes de tudo, um modo de pensar aberto e livre.

O reconhecimento dessas diferentes dimensões implícitas na formação universitária exige uma reorientação dos estudos com diplomados. Estes estudos deveriam conter objetivos não só relacionados à formação profissional, mas, especialmente, àqueles que se referem à natureza da formação oferecida e de seus diferentes impactos sociais. Trata-se de considerar não apenas a inserção profissional dos ex-alunos, mas, também, sua inserção social. Neste sentido, ocupam lugar destacado questões tais como: que tipo de mudança ele está provocando no meio no qual se insere? Em que sentido está exercendo sua cidadania? Que padrões éticos o orientam na sua vida pessoal e profissional?

A revisão da literatura educacional relacionada aos cursos de Psicologia no Brasil que trata dos estudos com diplomados e/ou "egressos" do ensino superior indica que os estudos realizados não abordam exclusivamente a trajetória profissional do ex-aluno e sua inserção profissional, mas também a natureza da formação oferecida, considerando seu impacto na vida profissional, além daqueles relacionados à natureza da estrutura curricular. De um modo geral são estudos com a finalidade de fornecer subsídios para a reformulação curricular, como os que apresentamos a seguir.

Alessi, Estevão e Barbieri (1983) tratam das opiniões dos alunos sobre a estrutura curricular no curso de Psicologia da FFCL-RP. Justifica-se a importância do levantamento em função da participação limitada dos estudantes nas decisões sobre o assunto. A centralização das decisões por parte do corpo docente 
tem resultado em mudanças formais, impossibilitando a introdução de mudanças nos conteúdos das diversas disciplinas que compõem a estrutura curricular. Os resultados deste estudo apontaram, entre outros problemas: excesso de disciplinas obrigatórias, número reduzido de docentes com predominância do modelo behaviorista na formação.

Cavalcante (1984) relata resultados de pesquisa sobre a dinâmica da carreira profissional de uma amostra de psicólogos egressos da UFBA. As respostas coletadas possibilitaram uma série de dados que permitiram visualizar o caminho profissional percorrido pelo psicólogo, uma vez que viabiliza sua inserção no mercado de trabalho.

Leda (1995) resgata os diversos momentos pelos quais passou o ensino superior da Psicologia na UFMA, acompanhando as inúmeras alterações sofridas por esta instituição, as demandas advindas da sociedade, além de realizar uma análise comparativa dos currículos contidos na proposta de criação do curso e de sua reestruturação, além daqueles que abordavam o novo direcionamento dado à formação profissional. Aponta como motivo preeminente para alteração do curso a insatisfação com as habilitações inicialmente oferecidas.

Pontes Neto (1985) relata um estudo preliminar a respeito da percepção dos alunos sobre o processo de aprendizagem, realizado no curso de Psicologia da UNESP. Aponta como respostas mais freqüentes: apresentação de objetivos em poucas disciplinas; estratégias de ensino utilizadas não atendem às expectativas dos alunos; a relação professor-aluno nem sempre facilita a aprendizagem. Conclui que, de um modo geral, a percepção dos alunos é negativa.

Silva (1999) verifica a percepção de docentes, supervisores de estágio e egressos sobre a formação ofertada no curso de Licenciatura e Formação de Psicólogos da Universidade Federal de Rondônia (UNIR), desde sua criação até 1996, detectando pontos positivos e negativos do processo, bem como as principais vicissitudes pelas quais passou o curso durante o seu desenvolvimento. Examinaram-se documentos de criação e reconhecimento do curso, o processo de regularização da grade curricular, da legislação interna da UNIR, livros-ata das reuniões ordinárias e extraordinárias do departamento de psicologia, e foram efetuadas entrevistas com todos os docentes lotados no departamento (no período de coleta de dados), além de entrevistas com egressos dos anos de 1993, 1994, 1995 e 1996. Os resultados revelaram que o curso enfrentou inúmeros problemas de ordem administrativa, legal e organizacional, não sendo capaz de superá-los, além de apresentarem uma desarticulação entre teoria e prática e o caráter pouco crítico da formação.

Versali (1989) detectou como o currículo do curso de Psicologia da UFPR contribui para a formação do psicólogo escolar, segundo a opinião deste profissional. O pressuposto básico do estudo é de que essa formação acadêmica deve favorecer o desenvolvimento da capacidade pessoal e profissional do psicólogo escolar, preparando-o para assumir a diversidade de funções exigidas pela comunidade escolar. 
Muito embora tenhamos anteriormente problematizado a tendência que se observa nos estudos realizados com diplomados, corroborada pelos objetivos dos estudos citados, a natureza deste ora apresentado não é diferente. A ausência de metodologias capazes de dar concretude a uma avaliação que contemple a diversidade de aspectos que compõem o processo formativo, assim como a diversidade de dimensões que podem caracterizar o profissional formado, reduz as possibilidades de compreensão do psicólogo que estamos formando.

De qualquer modo, não se pode negar a diversidade de aspectos considerados, bem como o potencial das contribuições que o estudo implica. Caberá aos gestores do curso, e àqueles que integram o coletivo que o implementa assimilar criticamente os resultados encontrados, a fim de buscar, no possível, aperfeiçoar o projeto pedagógico do curso.

\section{MÉTodo}

A amostra analisada é constituída de 38 ex-alunos do curso de Psicologia, equivalendo a $20,7 \%$ dos alunos que receberam o instrumento. O conceito de diplomados utilizado para a identificação dos alunos que comporiam o universo a ser investigado foi o recebimento de um diploma referente à conclusão de seu curso de origem.

$\mathrm{O}$ instrumento proposto, na forma de questionário, continha 20 questões fechadas, 16 do tipo likert e uma aberta para sugestões. Os questionários, com as instruções correspondentes, foram enviados pelo correio para o endereço constante nos registros da universidade, juntamente com um envelope selado para a resposta.

Os questionários devolvidos foram devidamente tabulados em banco de dados especialmente desenvolvido. Entretanto, a consulta a este banco de dados, por razoes técnicas, exigiu a recontagem manual de modo a permitir sua consolidação por curso, criando, assim, as condições para a geração das tabelas apresentadas a seguir.

\section{AnÁlise dos Resultados}

Para efeitos de análise, em cada questão procedeu-se à identificação da predominância de influência - grande ou pequena, como referência principal das análises efetuadas, uma vez que o objetivo é demarcar os referenciais mais importantes que caracterizam a opinião dos diplomados em questão sobre os aspectos considerados no instrumento. Cabe, ainda, ressaltar o fato de alguns dos questionários não estarem completamente preenchidos pelos respondentes, entretanto, mesmo assim, os dados correspondentes foram aproveitados para fins da análise efetuada.

Os resultados obtidos podem-se constituir em subsídios para o aperfeiçoamento pedagógico do curso de Psicologia. Recomenda-se, no entanto, cautela, para fins de conclusões mais definitivas em função de os dados se referirem apenas àqueles que responderam ao instrumento proposto. 
Tabela 1. Freqüência absoluta e relativa dos motivos para realizar o curso na UFF, por diplomados do Curso de Psicologia

\begin{tabular}{|l|c|c|}
\hline Motivos para realizar o curso na UFF & f & $\%$ \\
\hline Melhor curso pretendido & 3 & 8,8 \\
\hline Gratuita e em conta para a família & 28 & 82,4 \\
\hline Mais próximo da residência & 3 & 8,8 \\
\hline
\end{tabular}

O principal motivo apontado pelos respondentes ao instrumento de coleta de dados para optarem por realizar o curso na UFF foi o fato de a Universidade ser gratuita e mais em conta para a família $(82,4 \%$ ), conforme se depreende da Tabela 1. Destaca-se que a percepção sobre a qualidade do curso exerceu pouca influência na escolha, pois somente $8,8 \%$ marcaram a opção "melhor curso pretendido" e que também $8,8 \%$ escolheram realizar este curso pelo fato de ser "mais próximo da residência".

Estes dados são coerentes com os obtidos por Palharini, F. et al (2002b) em pesquisa realizada entre estudantes evadidos do curso de Psicologia. Verificou-se neste estudo que os estudantes evadidos não atribuíram importância à distância e à dificuldade de acesso à universidade, pois apenas 16,7\% deles consideraram que este item influiu na decisão de abandono. Somente $25,0 \%$ dos evadidos afirmaram que as despesas com a vida universitária exerceram grande influência no abandono. No entanto, merece destaque o fato de os diplomados usarem este critério para sua escolha, por considerarmos que a proximidade da IES com a residência não é um fator determinante na escolha de um curso, mesmo admitindo-se que este aspecto pode vir a interferir na continuidade dos estudos, dados os custos de deslocamento para o segmento com mais dificuldades econômicas.

Tabela 2. Freqüência absoluta e relativa das influências para escolha da carreira por diplomados em Psicologia

\begin{tabular}{|l|c|c|}
\hline Influência para escolha da carreira & $\mathbf{f}$ & $\mathbf{\%}$ \\
\hline Pai & 1 & 2,9 \\
\hline Mãe & 1 & 2,9 \\
\hline Outros parentes & 1 & 2,9 \\
\hline Amigo & 1 & 2,9 \\
\hline Professor & 1 & 2,9 \\
\hline Opção própria & 27 & 79,6 \\
\hline Testes vocacionais & 2 & 5,9 \\
\hline
\end{tabular}


Os diplomados afirmaram que o que mais influenciou na escolha da carreira, conforme depreendemos da Tabela 2, foi uma opção pessoal (79,6\%); as demais respostas distribuem-se entre testes vocacionais $(5,9 \%)$, o pai, a mãe, outros parentes, amigos e professor, cada uma delas com $2,9 \%$.

De acordo com a Tabela 3, observa-se que quase metade dos diplomados que responderam à pesquisa considera boa $(48,7 \%)$ ou ótima $(24,3 \%)$ a aquisição de conhecimentos relevantes para a atividade profissional. Esta predominância positiva das respostas é coerente com a expectativa generalizada, entre eles, de que o curso estivesse voltado para o exercício profissional $(75,5 \%)$, conforme veremos mais adiante. No entanto, os respondentes apontam que o curso não expressa de um modo tão satisfatório o perfil profissional, já que a maioria das respostas ficou entre bom $(43,2 \%)$ e regular $(35,2 \%)$.

A coerência do ciclo básico com o profissional é apontada pela maioria como boa $(45,9 \%)$ a regular $(40,5 \%)$. Os respondentes também afirmaram, em sua maioria, que a aquisição de conhecimentos relevantes para a atividade de pesquisa foi boa $(43,2 \%)$, tendendo a ótima $(27,0 \%)$ e, o mesmo ocorreu em relação à aquisição de conhecimentos relevantes para a atividade de ensino, porém em maior intensidade (36,2\% ótima e $38,8 \%$ boa).

A maior parte dos respondentes $(54,1 \%)$ assinalou como ótima a ênfase nos aspectos sociais e políticos durante o curso, revelando a preocupação do currículo do curso em desenvolver nos alunos não apenas habilidades para o futuro profissional, mas também um pensamento mais crítico a respeito do significado político da ação profissional do psicólogo. Quando perguntados sobre o estímulo por parte do corpo docente a reflexões sobre o papel do profissional na sociedade, as respostas predominantes o classificaram, também, como ótimo $(51,3 \%)$ e, dessa forma, podemos inferir que tanto pelo currículo, quanto por parte do corpo docente, o curso de Psicologia da UFF está orientado de modo marcante pela reflexão sobre os aspectos sociais e políticos da profissão.

Por outro lado não se evidenciam nas respostas destes diplomados, de modo tão marcante quanto sublinhamos nos aspectos sociais e políticos, a preocupação em adequar o conteúdo das disciplinas à aplicações no mercado de trabalho. As respostas foram, basicamente, regular $(45,9 \%)$ com tendência a bom, indicado por $32,4 \%$.

Em relação à interação ensino e pesquisa, as respostas se concentraram em grande parte em bom (45,9\%) e tenderam a regular (24,3\%). A interação ensino e extensão também concentrou a maioria das respostas em bom (43,2\%), porém $21,6 \%$ indicaram tendência para ótimo e o mesmo percentual para regular, o que denota uma percepção de tendência do curso mais forte em relação à extensão do que à pesquisa. Estas avaliações dos diplomados indicam que há, segundo a percepção dos mesmos, um certo equilíbrio no curso de Psicologia da UFF em relação às atividades de ensino, pesquisa e extensão, mas com predomínio da última atividade. 
Tabela 3. Freqüência absoluta e relativa da avaliação de aspectos do curso realizado por diplomados em Psicologia

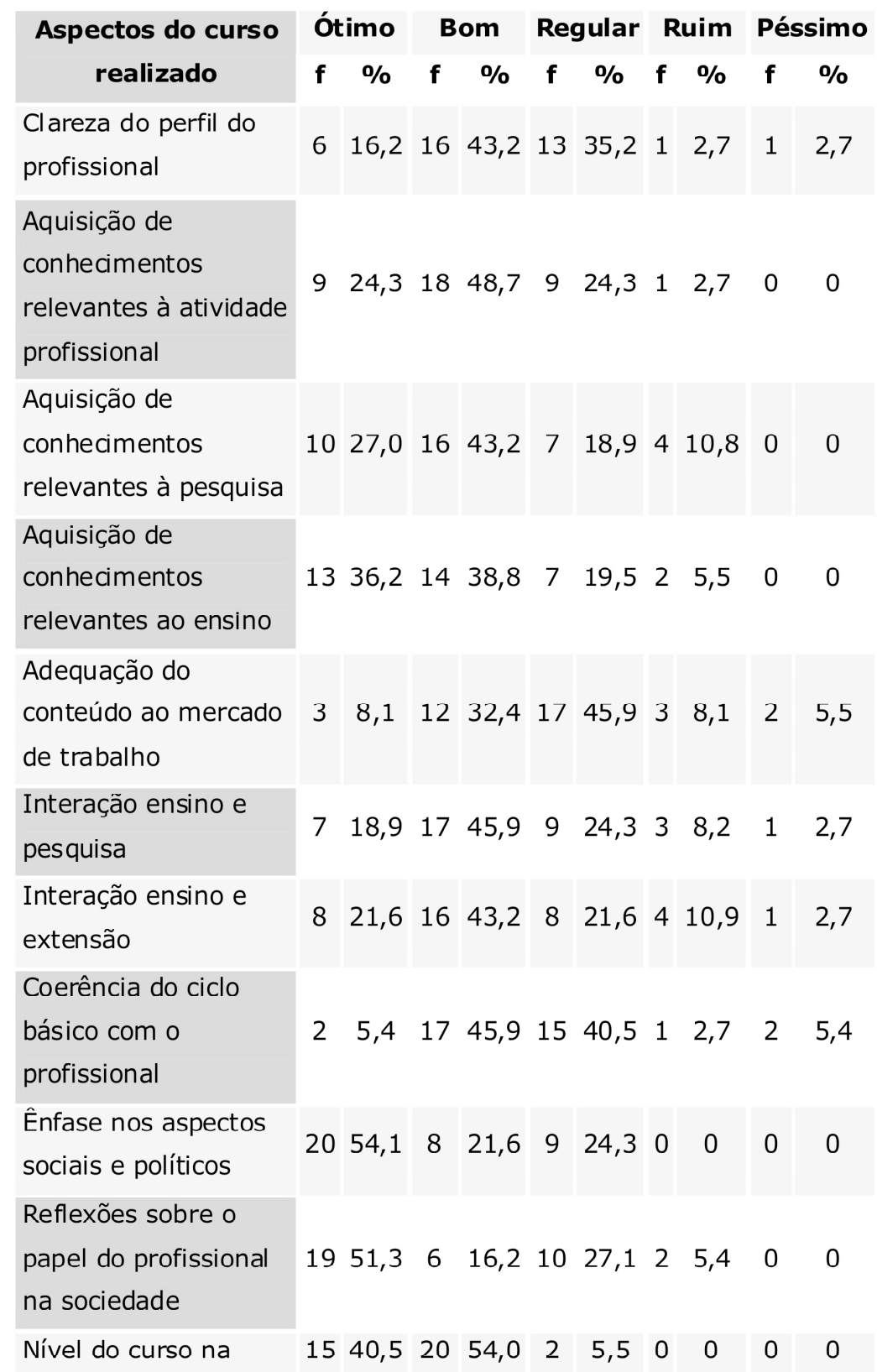

Quanto ao nível do curso na época em que se graduou, a maioria dos respondentes considerou bom (54,0\%) seguido de ótimo (40,5\%); talvez por isto muitos tenham respondido que recomendariam o curso a um amigo ou parente 
$(91,4 \%)$. O confronto destes dados com aqueles obtidos nos estudos com os evadidos indica coerência de percepção pelos dois grupos de ex-alunos. Verificou-se, neste estudo, que nenhum evadido indicou decepção em relação à qualidade do curso e $83,4 \%$ deles não procuraram o mesmo curso em outra instituição.

As respostas sobre integração aluno e professor se concentraram no item bom $(51,3 \%)$ com grande tendência para ótimo $(43,2 \%)$, de acordo com a Tabela 4. Isto revela que os professores procuram se relacionar de forma positiva com os alunos, o que tende a facilitar o processo ensino-aprendizagem.

Tabela 4. Freqüência absoluta e relativa da avaliação dos diplomados em psicologia sobre características dos docentes do curso

\begin{tabular}{|l|c|c|c|c|c|c|c|c|c|c|}
\hline \multirow{2}{*}{ Características dos docentes } & \multicolumn{2}{|c|}{ Ótimo } & \multicolumn{2}{|c|}{ Bom } & \multicolumn{2}{|c|}{ Regular } & \multicolumn{2}{|c|}{ Ruim } & \multicolumn{2}{|c|}{ Péssimo } \\
\hline f & $\mathbf{\%}$ & $\mathbf{f}$ & $\mathbf{\%}$ & $\mathbf{F}$ & $\mathbf{\%}$ & $\mathbf{f}$ & $\mathbf{\%}$ & $\mathbf{f}$ & $\%$ \\
\hline Integração aluno X professor & 16 & 43,2 & 19 & 51,3 & 1 & 2,7 & 1 & 2,7 & 0 & 0 \\
\hline Domínio do conteúdo & 17 & 45,9 & 17 & 45,9 & 3 & 8,2 & 0 & 0 & 0 & 0 \\
\hline Metodologia de ensino & 4 & 11,3 & 18 & 50,0 & 12 & 33,3 & 1 & 2,7 & 1 & 2,7 \\
\hline
\end{tabular}

Segundo os dados da Tabela 4, a maioria dos alunos afirmou que o corpo docente domina o conteúdo de forma ótima $(45,9 \%)$ ou boa $(45,9 \%)$, não havendo nenhuma resposta péssimo. A questão da metodologia de ensino, que foi percebida pelos respondentes como boa $(50,0 \%)$ com tendência a regular $(33,3 \%)$ indica um aspecto que pode ser melhorado no que tange ao exercício da atividade docente.

Tomando-se como referência o item "aquisição de conhecimentos relevantes para a atividade profissional" que apresentou o terceiro maior índice no somatório de respostas nas opções "ótimo" e "bom" (ver Tabela 3), depreende-se existir coerência entre a avaliação do curso e a do corpo docente. Os respondentes perceberam que este último conhecia bem o conteúdo e que o transmitia de forma que os alunos obtivessem aquisição satisfatória de conhecimentos, porém poderiam ter um resultado ainda melhor se a metodologia de ensino utilizada, segundo os mesmos respondentes, fosse mais compatibilizada com o interesse dos alunos.

Tabela 5. Freqüência absoluta e relativa das expectativas dos diplomados em psicologia, por ocasião do ingresso, em relação ao curso

\begin{tabular}{|l|c|c|}
\hline Expectativas em relação ao curso & f & $\%$ \\
\hline Ascensão na carreira & 0 & 0 \\
\hline Exercicio profissional & 24 & 75 \\
\hline Adquirir título & 1 & 3,1 \\
\hline Formação para pesquisa & 2 & 6,2 \\
\hline Formação voltada para o bem comum & 5 & 15,7 \\
\hline
\end{tabular}


Quando perguntados sobre o que mais esperavam do curso de graduação, a resposta obtida foi que este oferecia uma formação voltada para o exercício profissional $(75,0 \%)$, seguido de uma formação orientada para o bem comum, isto é, visando a melhoria de vida da sociedade, conforme se depreende da Tabela 5.

Tabela 6. Freqüência relativa e absoluta da opinião dos diplomados em psicologia sobre a relação entre curso realizado e emprego atual

\begin{tabular}{|l|c|c|c|c|c|c|}
\hline \multicolumn{1}{|c|}{ Relação curso/emprego } & \multicolumn{2}{|c|}{ Sim } & \multicolumn{2}{c|}{ Parcial } & Não \\
\hline Curso realizado ajudou na carreira profissional & f & $\%$ & f & $\%$ & f & $\%$ \\
\hline Atua na área em que se graduou & 28,6 & 2 & 6,2 & 2 & 6,2 \\
\hline
\end{tabular}

Segundo os respondentes, o curso realizado ajudou em suas carreiras profissionais $(87,6 \%)$ conforme se observa na Tabela 6 . Este dado é coerente com o fato de a maioria ter afirmado estar empregada atualmente na área em que se graduou $(78,1 \%)$, como revela a Tabela 6 .

Tabela 7. Freqüência absoluta e relativa dos motivos de diplomados em psicologia para atuar em outra área

\begin{tabular}{|l|l|c|}
\hline Motivo para atuar em outra área & f & $\%$ \\
\hline Campo de trabalho restrito & 0 & 0 \\
\hline Falta de oportunidade & 2 & 66,7 \\
\hline Trabalna em negócio da família & 1 & 33,3 \\
\hline
\end{tabular}

Os diplomados que disseram não estar trabalhando na sua área de graduação $(12,5 \%)$, de acordo com a Tabela 6 , deram como principal motivo a falta de oportunidade $(66,7 \%)$, seguido de estarem trabalhando em negócio da família (ver Tabela 7).

Tabela 8. Freqüência absoluta e relativa da condição de empregabilidade dos diplomados em psicologia

\begin{tabular}{|l|c|c|c|c|}
\hline \multicolumn{1}{|c|}{ Condição no emprego } & \multicolumn{2}{c|}{ Sim } & \multicolumn{2}{c|}{ Não } \\
\hline Encontra-se atualmente empregado & f & $\%$ & $\mathbf{f}$ & $\mathbf{\%}$ \\
\hline Já recebeu incentivo e/ou promoção no emprego atual & 32 & 86,5 & 5 & 13,5 \\
\hline
\end{tabular}

Considerando que $75 \%$ dos respondentes esperavam do curso uma formação orientada para o exercício profissional (ver Tabela 5), pode-se afirmar que o curso de Psicologia atende às expectativas da maioria dos alunos, uma 
vez que grande parte está empregada na área em que se graduou $(78,1 \%)$, conforme nos mostra a Tabela 6 , e está progredindo no trabalho $(61,3 \%)$, conforme revela a Tabela 8 .

A maioria dos que estão atualmente trabalhando está em empresas ou instituições públicas $(40,6 \%)$, e os outros em empresas ou instituições privadas $(25,0 \%)$ e em instituições de ensino $(12,5 \%)$, conforme revela a Tabela 9. Este dado merece atenção especial se considerarmos o grau de exigência presente nas provas e concursos para entrada em instituições públicas.

Tabela 9. Freqüência absoluta e relativa da natureza do emprego e/ou local de trabalho dos diplomados em psicologia

\begin{tabular}{|l|c|c|}
\hline Local de Trabalho & f & \% \\
\hline Empresa Privada & 8 & 25,0 \\
\hline Empresa Publica & 13 & 40,6 \\
\hline Empresa Mista & 1 & 3,1 \\
\hline Serviços & 3 & 9,4 \\
\hline Instituição de Ensino & 4 & 12,5 \\
\hline Outros & 3 & 9,4 \\
\hline
\end{tabular}

A maioria dos respondentes também afirmou estar progredindo constantemente em seu trabalho (90,0\%), de acordo com a Tabela 10 , o que é coerente com as respostas mostradas na Tabela 8 em que mais da metade dos entrevistados afirma já ter recebido incentivo e/ou promoção (61,3\%). Estes dados reafirmam que a aquisição de conhecimentos para a atividade profissional no curso é boa.

Tabela 10. Freqüência absoluta e relativa da situação atual no trabalho por parte dos diplomados em psicologia

Nos seus respectivos locais de trabalho, os respondentes atuam em diversas funções, principalmente naquelas relacionadas a contato com o cliente $(34,8 \%)$, atendimento $(17,4 \%)$ e outras $(17,4 \%)$, de acordo com a Tabela 11 .

\begin{tabular}{|l|c|c|}
\hline Situação atual no trabalho & f & \% \\
\hline Progredindo constantemente & 27 & 90,0 \\
\hline Merecedor de promoção & 1 & 3,4 \\
\hline Está desaprendendo o que sabe & 2 & 6,6 \\
\hline
\end{tabular}


Tabela 11. Freqüência absoluta e relativa da natureza das funções exercidas por diplomados em psicologia

\begin{tabular}{|l|c|c|}
\hline Natureza das funções exercidas & $\mathbf{f}$ & $\mathbf{\%}$ \\
\hline Docência & 2 & 8,7 \\
\hline Contábil & 1 & 4,3 \\
\hline Coordenação & 2 & 8,7 \\
\hline Atendimento & 4 & 17,4 \\
\hline Treinamento pessoal & 2 & 8,7 \\
\hline Contato c/ clientela & 8 & 34,8 \\
\hline Outros & 4 & 17,4 \\
\hline
\end{tabular}

Os diplomados participantes desta pesquisa afirmam que tiveram pouca (45,9\%), ou nenhuma $(39,2 \%)$ dificuldade para a conclusão do curso, de acordo com a Tabela 12. Estas respostas merecem atenção por parte dos responsáveis pelo curso, uma vez ser esperado de um curso universitário pelo menos um grau mediano de dificuldade. Não se pode descartar, no entanto, que tais respostas sejam dependentes de características da amostra que respondeu ao instrumento.

Tabela 12. Freqüência absoluta e relativa das opiniões dos diplomados em psicologia sobre o grau de dificuldade para conclusão do curso

\begin{tabular}{|l|c|c|}
\hline Grau de dificuldade para realização do curso & $\mathbf{f}$ & $\mathbf{\%}$ \\
\hline Nenhum & 13 & 35,2 \\
\hline Pouco & 17 & 45,9 \\
\hline Médio & 6 & 16,2 \\
\hline Muito & 1 & 2,7 \\
\hline
\end{tabular}

Cabe destacar também que tais dados são congruentes com aqueles obtidos por Palharini, F. et al. (2002a) em pesquisa com estudantes evadidos do curso de Psicologia no mesmo período. Neste caso, verificou-se que os evadidos do curso de Psicologia, em sua grande maioria $(75,0 \%)$, não tiveram dificuldade de obter bom desempenho no curso.

A maior parte dos diplomados não realizou outro curso superior $(83,8 \%) \mathrm{e}$, quando o fizeram foi com o objetivo de adquirir novos conhecimentos $(50,0 \%)$ e ampliar o campo de trabalho (50,0\%). Estes dados são coerentes com a afirmação por parte dos respondentes de que a aquisição de conhecimentos relevantes para a atividade profissional é boa, reduzindo a necessidade de complementação através de outro curso superior, o que se alia ao fato de a maioria dos diplomados estar empregada em sua área de graduação. Eles também são coerentes com aqueles dados encontrados por Palharini et al (2002b) nos quais verificou-se que a maioria $(75,0 \%$ dos evadidos) não procurou outro curso de nível superior. 
Tabela 13. Freqüência absoluta e relativa dos cursos realizados após a graduação, por diplomados em psicologia

\begin{tabular}{|l|c|c|}
\hline Curso realizado após a graduação & f & \% \\
\hline Especialização & 20 & 57,1 \\
\hline Especialização e mestrado & 8 & 22,8 \\
\hline Mestrado & 1 & 2,9 \\
\hline Nenhum curso & 6 & 17,1 \\
\hline
\end{tabular}

A maioria dos diplomados pesquisados respondeu que depois do curso de graduação realizou um curso de especialização (57,1\%), especialização e mestrado $(22,8 \%)$ e, somente $17,1 \%$ não fizeram nenhum curso após a graduação, de acordo com a Tabela 13. Apesar disto, quase todos têm interesse em fazer um curso de pós-graduação na UFF $(91,7 \%)$. Este fenômeno pode ser justificado pelo fato de a maioria ter ficado satisfeita com o seu curso de graduação e, portanto tende a acreditar que, se a graduação foi boa e atingiu às expectativas, a pós-graduação também o fará. Deve-se destacar que o interesse por um curso de especialização foi expresso por $30,8 \%$ dos respondentes, o que pode significar que existe um grupo de diplomados que deseja fazer uma segunda especialização.

Dos diplomados que querem fazer pós-graduação na UFF, a maioria tem interesse em um curso de mestrado $(50,0 \%)$, seguido de um curso de especialização $(30,8 \%)$ e de doutorado $(19,2 \%)$.

Tabela 14. Freqüência absoluta e relativa da opinião dos diplomados sobre situação atual do curso de psicologia

\begin{tabular}{|l|c|c|}
\hline Situação atual do curso & f & $\%$ \\
\hline Melhorou & 5 & 13,5 \\
\hline Está na mesma & 8 & 21,6 \\
\hline Piorou bastante & 0 & 0 \\
\hline Não sei opinar & 24 & 64,8 \\
\hline
\end{tabular}

A grande maioria dos diplomados respondeu que se interessa por notícias que envolvem a UFF $(97,3 \%)$ e mais da metade afirmou que, de acordo com notícias recebidas, ou segundo contatos mantidos, a UFF se integra à vida da sociedade $(61,3 \%)$ e cumpre seu papel na comunidade $(29,0 \%)$. Por outro lado, grande parte dos diplomados não soube opinar sobre como anda o curso de Psicologia atualmente $(64,8 \%)$, conforme mostra a Tabela 14 , uma vez que há uma falta de contato com a instituição indicada por uma quantidade significativa de entrevistados $(56,8 \%)$. 


\section{SíNTESE DOS RESULTADOS}

A título de conclusão depreende-se das análises efetuadas que os diplomados do curso de Psicologia da UFF que responderam ao instrumento proposto tendem predominantemente a escolher esse curso pelo fato dessa instituição ser gratuita. E a decisão por esta escolha é atribuída por eles à uma decisão pessoal. Quando solicitados a avaliar diferentes dimensões do curso realizado, os respondentes tendem a considerar que o perfil profissional, decorrente da formação recebida, se distribui majoritariamente entre regular e bom. Quando foram solicitados a avaliar o curso de um modo geral, verificou-se forte concentração na categoria "ótimo".

Entretanto, deve-se destacar o fato de que os aspectos considerados mais positivos são aqueles relacionados à "ênfase nos aspectos sociais e políticos da profissão", bem como às "reflexões sobre o papel do profissional na sociedade". Os aspectos considerados como menos satisfatórios (mas não necessariamente insatisfatórios) são: "adequação do conteúdo com o mercado de trabalho" e a "coerência do ciclo básico com o profissional". Cabe também destacar o fato de os respondentes terem afirmado de modo expressivo que o grau de dificuldade para conclusão do curso foi praticamente pouco ou nenhum. É possível que isso esteja relacionado à metodologia de ensino, mais especificamente no que tange à avaliação dos conteúdos assimilados. A hipótese de que o grau de dificuldade para a realização do curso esteja relacionado à ênfase do curso nos aspectos reflexivos não se sustenta, quando consideramos que os respondentes estão de forma amplamente majoritária empregados e atuando na área em que se formaram. Nesta perspectiva torna-se possível formular, a partir dos dados obtidos, a hipótese de que a formação recebida no curso de Psicologia da UFF enquadra-se mais na perspectiva de educação superior e não na de ensino superior, conforme diferenciação feita por Edgard Morin (2000b).

As impressões por parte dos respondentes a respeito da formação recebida tendem a apontar que ela se inclina mais para uma formação geral, reflexiva e crítica com relação à Psicologia do que para o ensino de habilidades e competências necessárias para o mercado de trabalho, nos termos propostos por Morin (2000a; 2000b). Infelizmente este estudo não considerou, por ocasião de seu planejamento, a natureza da inserção social dos respondentes. Avançar, portanto, na compreensão da efetividade desta formação, para fins de apreender seu papel na transformação do contexto social em que os diplomados se inserem é desejável do ponto de vista pedagógico.

No que tange às características dos docentes, destaca-se a avaliação positiva da integração com os alunos, bem como o domínio do conteúdo por boa parte dos docentes. No entanto, os mesmos diplomados respondentes são críticos quando se trata de considerar a metodologia utilizada pelos docentes para o ensino. Estas impressões por parte da amostra considerada guardam forte correspondência com os resultados observados em estudo específico sobre avaliação de disciplinas (CPAIUFF, 2002). Assim, com o objetivo de fortalecer o curso de Psicologia, recomenda-se, a partir destes estudos, que docentes busquem rever a metodologia de ensino utilizada e, se necessário, requalificarem-se quanto a este aspecto. 
Quando de seu ingresso no curso de Psicologia da UFF, os respondentes indicam que esperavam mais uma formação orientada para o mercado de traba1ho. Não são muitos, ao contrário do que se esperava, aqueles que esperavam uma formação mais "orientada para o bem comum". Talvez por isso os diplomados considerados tenham sido mais críticos quanto à adequação do conteúdo do curso ao mercado de trabalho. De qualquer modo, destaca-se o fato de a quase totalidade destes ex-estudantes terem considerado que o curso ajudou na sua carreira profissional, bem como o fato de a mesma proporção indicar que atua na área em que se formou, além de assinalar que estão progredindo no seu emprego atual.

Quando consideramos a natureza da inserção profissional verificamos que os respondentes em questão estão majoritariamente empregados em "empresas" públicas e, em seguida, em empresas privadas, além de uma parcela considerável inserir-se em instituições de ensino. As funções que exercem distribuem-se em ordem crescente de grandeza entre "contato com clientela", 'atendimento', 'outros' (não especificado), docência, treinamento, coordenação e atividades contábeis.

\section{Notas}

${ }^{1}$ A equipe que conduziu originalmente a pesquisa, coordenada pela professora Rosangela Lopes Lima, foi responsável pelo planejamento, elaboração do instrumento, aplicação e tabulação das respostas em Banco de Dados.

\section{REFERÊNCIAS}

ALESSI, M. P; ESTEVÃO, R; BARBIERI, M. R. Opiniões de estudantes do curso de Psicologia. Ciência e Cultura, Campinas, v. 35 n. 7, p. 25-36, 1983.

CAVALCANTE, M. L. do P. O psicólogo egresso na UFBA: subsídios para análise da força de trabalho em Psicologia na Grande Salvador. 1984. Dissertação (Mestrado)-Universidade Federal da Bahia, Salvador, 1984.

CPAIUFF Resultados da Avaliação de Disciplinas na UFF em 2001: relatório geral de cursos. Niterói: PROAC/UFF, 2002.

HALPERN, D. F. Student outcomes assessment: what institutions stand to gain. New Directions for Higher Education, USA, v. 59, n.3, p. 45-63, 1987.

LEDA, D. B. O curso de Psicologia na Universidade Federal do Maranhão: trajetória de um processo de formação. Ciência e Cultura, Campinas, v. 47/II, n. 7, p. 45-58, 1995.

MORIN, E. A Cabeça Bem Feita: repensar a reforma, reformar o pensamento. Rio de Janeiro: Bertrand Russel, 2000a.

$2000 b$.

. Os sete saberes necessários a educação do futuro. Rio de Janeiro: Cortez, 
PALHARINI, F. A. Caderno NUPES: um novo protagonista na formulação teórica para o Ensino Superior. In: SGUISSARD, W.; MOROSINI, M. (Org.). Educação Superior em Periódicos Nacionais. Vitória: CNPq/ UFES, 1998. p. 96-112.

. O Estado do PAIUB em Universidades Federais da Região Sul e Sudeste: tormento ou paixão. 1999. Tese (Doutorado)-UFF, Niterói. 1999.

PALHARINI, F. A. et al. Psicologia: articulações entre a produção de conhecimentos e a formação em psicologia. In: CONGRESSO BRASILEIRO DE PSICOLOGIA: CIÊNCIA E PROFISSÃO, 1., 2002, São Paulo. Anais... São Paulo: Fórum de Entidades Brasileiras de Psicologia, 2002a, p.13. Resumo de mesa redonda.

- O curso de Psicologia na opinião de diplomados e evadidos. In: CONGRESSO BRASILEIRO DE PSICOLOGIA: CIÊNCIA E PROFISSÃO, 1., 2002. São Paulo: Fórum de Entidades Nacionais de Psicologia Brasileira/ Conselho Regional de Psicologia, 2002b.

PONTES NETO, J. A. S. Percepção de alunos sobre o processo ensino aprendizagem em um curso de Psicologia. Ciência e Cultura, Campinas, v. 37, n. 5 , p. 7-21, 1985 .

PROAC/CPAIUFF. Valeu a Pena? Niterói: 1999. Relatório de pesquisa n ${ }^{\circ} 1$

RESNICK, D. P.; GOULDEN, M. Assesment, curriculum and expansion: a historical perspective. In: HALPERN, D. F. New Directions for Higher Education. Student outcomes assessment: what institutions stand to gain, 1987, p. 64-73.

SCHWARTZMAN, S. Uma Universidade, várias trajetórias. Série Análises preliminares. Cadernos NUPES, São Paulo, n. 1, p.1-22, 1991.

SCHWARTZMAN, S.; CASTRO, M. H. M. C. A Trajetória acadêmica e profissional dos alunos da USP. Documento de Trabalho. Cadernos NUPES, São Paulo, n. 2, p. 1-19, 1991.

SILVA, J. C. B. As Percepções de docentes e egressos sobre o curso de licenciatura e formação de psicólogos da Fundação Universidade de Rondônia UNIR. 1999. Dissertação (Mestrado)-Universidade Federal do Rio de Janeiro, Rio de Janeiro, 1999.

VERSALLI, A. A formação do psicólogo escolar, egresso da Universidade Federal do Paraná: o estudo do currículo. 1989. Dissertação (Mestrado)-Universidade Federal do Paraná, Curitiba, 1989.

Recebido em: dezembro de 2002

Aceito em: maio de 2008 